\title{
Computed Tomography Image of Extrahepatic Portal Vein Obstruction
}

\author{
Toshihiko Kakiuchi ${ }^{1}$, Aiko Nakayama ${ }^{1}$, Junichi Nojiri ${ }^{2}$ and Muneaki Matsuo ${ }^{1}$
}

Key words: extrahepatic portal vein obstruction, computed tomography during arterial portography, dynamic computed tomography, magnetic resonance portography

(Intern Med 58: 1965-1966, 2019)

(DOI: 10.2169/internalmedicine.2297-18)

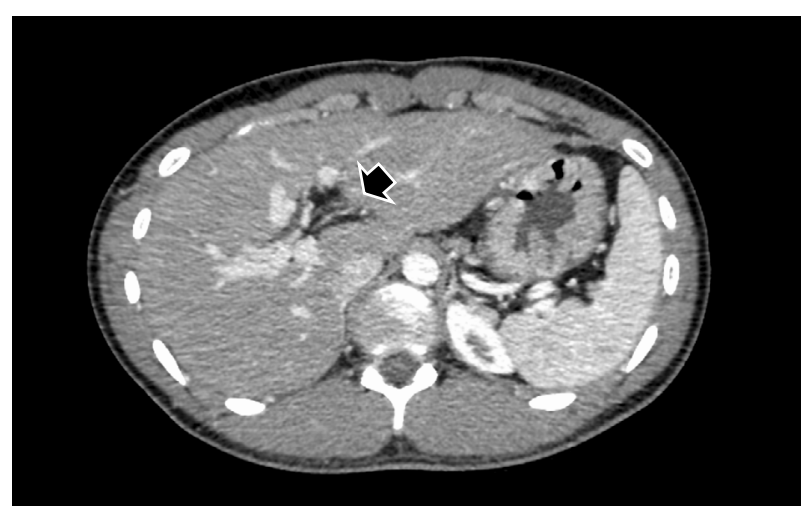

Absence of the trunk of the portal vein

Picture 1.
A 17-year-old man was referred with a history of abdominal pain of several years duration. Physical examination was normal with normal hepatic-biliary enzyme levels and slight liver disfunction with aspartate aminotransferase/alanine aminotransferase of 33/57 IU/L. During contrast-enhanced abdominal computed tomography (CT), the trunk of the portal vein could not be identified (Picture 1, arrow). Based on the findings of angiography and CT during arterial portography (CTAP), extrahepatic portal vein obstruction was diagnosed. The blood flow from the splenic vein flowed backwards into the superior mesenteric vein (SMV); subsequently, the SMV blood flowed into the gastrocolic trunk and then into the intrahepatic portal vein (Picture 2). According to the 3D CT with CTAP data, the trunk of the por-
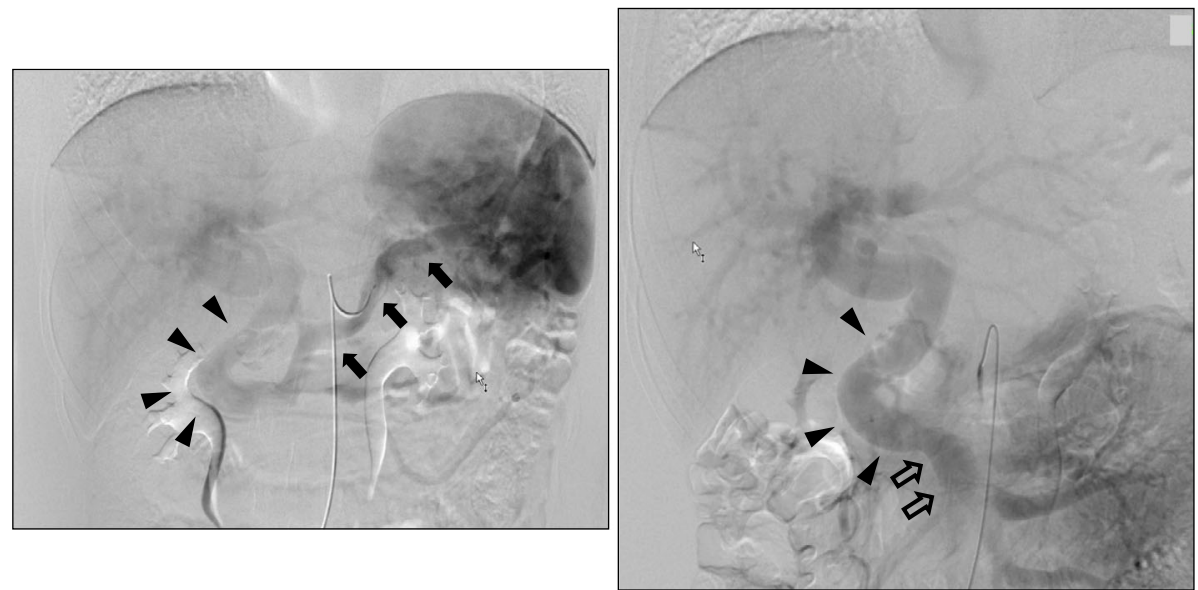

$$
\begin{aligned}
& \text { Splenic vein } \\
& \text { SMV } \\
& \text { GCT: Gastrocolic trunk }
\end{aligned}
$$

Picture 2.

\footnotetext{
${ }^{1}$ Departments of Pediatrics, Faculty of Medicine, Saga University, Japan and ${ }^{2}$ Departments of Radiology, Faculty of Medicine, Saga University, Japan

Received: October 23, 2018; Accepted: January 7, 2019; Advance Publication by J-STAGE: February 25, 2019

Correspondence to Dr. Toshihiko Kakiuchi, kakiucht@cc.saga-u.ac.jp
} 


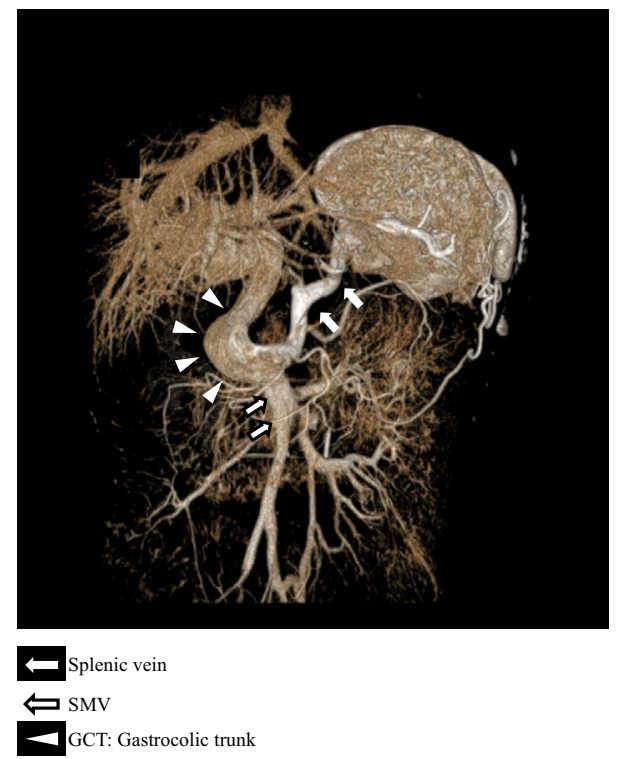

Picture 3. tal vein could not be identified and the expanded gastrocolic trunk was stuck in the intrahepatic portal vein (Picture 3). For making a diagnosis of hepatic portal vein obstruction, dynamic CT and magnetic resonance portography are both considered to be highly useful (1). When a more detailed assessment of the finer vascular structures or the blood flow direction is required, then angiographic and CTAP examinations are considered to provide highly useful information.

The authors state that they have no Conflict of Interest (COI).

\section{Reference}

1. Pargewar SS, Desai SN, Rajesh S, Singh VP, Arora A, Mukund A. Imaging and radiology interventions in extra-hepatic portal vein obstruction. World J Radiol 8: 556-570, 2016.

The Internal Medicine is an Open Access journal distributed under the Creative Commons Attribution-NonCommercial-NoDerivatives 4.0 International License. To view the details of this license, please visit (https://creativecommons.org/licenses/ by-nc-nd/4.0/).

(C) 2019 The Japanese Society of Internal Medicine Intern Med 58: 1965-1966, 2019 